\title{
Active carbons for selective flotation of primary gold-copper-porphyry ore
}

\author{
Margarita Gurman ${ }^{1 *}$ and Abdakim Ashimbayev ${ }^{2}$ \\ ${ }^{1}$ Mining Institute FEB RAS, 51 Turgenev st., Khabarovsk, 680000, Russia; \\ ${ }^{2}$ The Razzakov Kyrgyz State University, 720044, Kyrgyzstan, Bishkek, Mira Ave., 66
}

\begin{abstract}
The results of a study on the flotation of gold-copper-porphyry ore are presented. The quality of the obtained concentrates is confirmed by the efficiency of using activated carbon to reduce the excess of reagents accumulating in the collective concentrates. Detailed studies of concentrates of copper selection using scanning electron microscopy revealed the presence of carbon in their composition. On the surface of gold and chalcopyrite particles, thin coal deposits and coatings were observed. Flotation of particles of gold and sulfide minerals can probably be improved by naturally hydrophobic or hydrophobized coal particles. "Carbon" coatings are selective with respect to the surface of sulfide minerals. No coal coatings were found on the surface of quartz grains and crystals.
\end{abstract}

Keywords: gold-copper-porphyry ore, activated carbon, gold and chalcopyrite surfaces, carbonaceous coatings, hydrophobic and hydrophobized particles

\section{Introduction}

It is known that the schemes of collective flotation with a subsequent selection of the collective concentrate have a technological advantage, especially with respect to poor finely disseminated ores, namely: at the beginning of the process, the bulk of the host rocks is separated into tailings with a minimum metal content, and then the collective concentrate being small part of the original ore undergoes flotation $[1,2]$. To improve the conditions for the separation of collective concentrates before the selection cycle, various methods of removing the collector from the surface of minerals and from the liquid phase of the pulp can be used. Desorption of the collector can be carried out, for example, by treatment with sodium sulfide, followed by dilution and washing; filtration and thickening; heat treatment in a highly alkaline environment in autoclaves; roasting the concentrate; using ultrasound [3], etc. An expedient way to remove excess collector from the liquid phase of the pulp and partial desorption of the collector from the surface of minerals of collective concentrates is its absorption by active carbons [1, 4]. They can be loaded into the pulp during conditioning. As is known, activated carbons are porous adsorbents consisting of randomly arranged packs of carbon rings. The adsorption properties of activated carbons are mainly determined by their porosity and extremely developed specific surface area. Typically, the

* Corresponding author: mgurman@yandex.ru 
surface available for adsorption of active carbons is estimated at $400-700 \mathrm{~m}^{2} / \mathrm{g}$. According to Bogdanov, desorption of xanthate from the surface of sulfide minerals apparently occurs in several stages. Active carbon absorbs xanthate from the solution and thereby shifts the equilibrium towards further transition of xanthate ions from the surface of the mineral into the solution [3]. Thus, the stability of the selective separation of minerals is maintained. However, in the process of flotation, a certain amount of coal can pass into concentrate [4], mainly, very fine particles. When conditioning the pulp for the purpose of desorption by active carbon of excess collector and foaming agent, it is likely that some of the reagents still remain in solution. Pine oil has collecting properties for coal [5], the hydroxyl groups of the foaming agent can be fixed by physical adsorption on the surface of slightly oxidized natural hydrophobic minerals (coal), and apolar radicals directed into water impair its interaction with the surface [2]; the hydrophobicity and, consequently, the flotation of coal particles increases. In the copper selection cycle, stirring may increase the likelihood of collision of hydrophobic coal particles with hydrophobized particles of sulfide minerals and free gold. The small size of coal particles determines their large specific surface area and adsorption capacity. In the event of a collision, flotation-active coal particles in the pulp adhere to the hydrophobized areas of the surface of sulfide minerals (and free gold) and float.

\section{Methodology}

The object of the study was technological samples of the poor primary gold-copperporphyry ore of the Malmyzh field (Khabarovsk Territory) with a copper content of 0.44$0.5 \%$, gold $-0.39-0.44 \mathrm{~g} / \mathrm{t}$, silver $-1.13-1.64 \mathrm{~g} / \mathrm{t}$, chalcopyrite content being $1.3-1.5 \%$ and pyrite $-2.8-3 \%$. Flotation studies were carried out according to a collective scheme followed by incomplete selection of the collective concentrate. Grinding time varied in the range of 5-18 minutes, while the feed size varied within $57-87 \%$ of the class $0.071 \mathrm{~mm}$. Flotation tests were carried out in laboratory flotation machines with chambers volume V$0.5(0.25) 1$ in an open cycle. Reagent mode of collective selective flotation: liquid glass $(0.5 \%)-150 \mathrm{~g} / \mathrm{t}$ (t agit. $-2 \mathrm{~min})$, diisobutyl dithiophosphate $(0.1 \%)-25 \mathrm{~g} / \mathrm{t}$; pine oil - 5$10 \mathrm{~g} / \mathrm{t}$ ( $\mathrm{t}$ agit. $-0.5 \mathrm{~min})$; activated carbon $-200 \mathrm{~g} / \mathrm{t}$ ( $\mathrm{t}$ agit $-10 \mathrm{~min})$, DNP $(0.5 \%)-150$ $\mathrm{g} / \mathrm{t}$ ( $\mathrm{t}$ agit. $-5 \mathrm{~min})$. The flotation time was 10 minutes. Petrographic, mineragraphic and mineralogical studies of ore and concentration products were carried out using optical and electron microscopy. During the research, analytical and physicochemical methods of analysis were used (gravimetric and titrimetric; spectrochemical and emission spectral; spectrophotometric, atomic absorption).
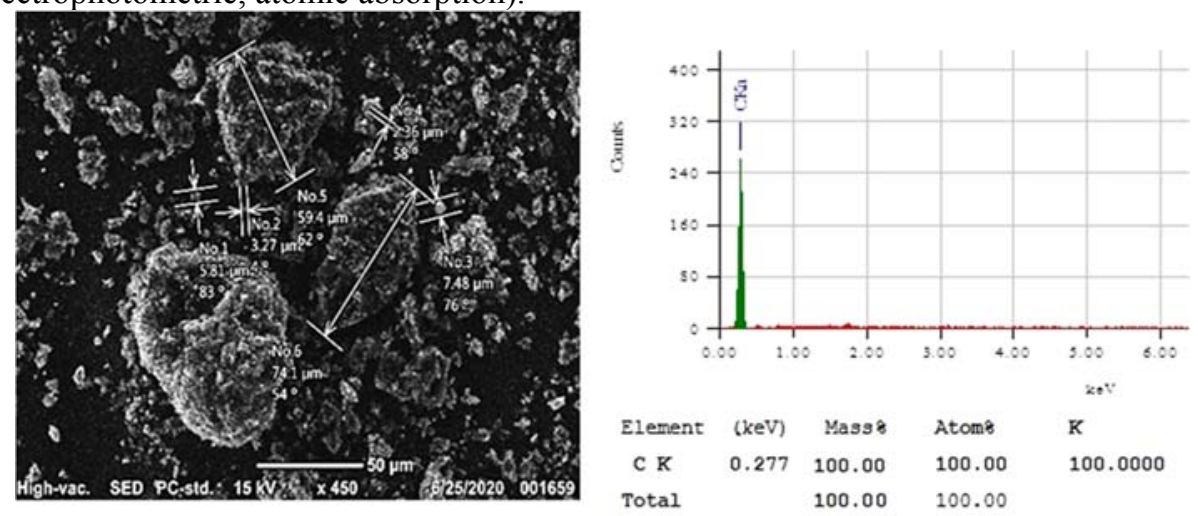

Fig. 1. Particles of activated carbon less than $90 \mu \mathrm{m}$ 


\section{Results and Discussion}

Based on the flotation studies of the primary poor gold-copper-porphyry ore of the Malmyzh field (Khabarovsk Territory) carried out earlier at the Institute of Mining of the FEB RAS, the possibility of extracting $88-93 \%$ of copper, $61-78 \%$ of gold, $73-83 \%$ of silver into collective gold-copper-sulfide concentrates has been shown, with a $\mathrm{Cu}$ content of 5-6.4\%; Au 3.5-5.4 g/t; Ag 12-14.7 g/t. At the same time, 90-93\% of ore mass with a content of $0.03-0.05 \% \mathrm{Cu}, 0.103-0.12 \mathrm{~g} / \mathrm{t} \mathrm{Au}$ and $0.2-0.3 \mathrm{~g} / \mathrm{t} \mathrm{Ag}$ can be removed from the process into the tailings. The resulting concentrate was subjected to selective flotation. Since the concentrate contains gold, copper and iron sulfides, to increase the contrast of the separation of chalcopyrite and pyrite, aeration of the pulp was carried out before copper selection; active carbon was added to absorb the excess collector accumulated in the collective concentrates; disodium phosphate was used to improve the separation of gold and chalcopyrite from pyrite. In the obtained concentrates of copper selection, the mass fraction of copper was 15.1-23.1\%, $\mathrm{Au}-2-11.7 \mathrm{~g} / \mathrm{t}$ and $\mathrm{Ag}-26-31.43 \mathrm{~g} / \mathrm{t}$, depending on the size of the crushed ore [6].

Finely ground flotation products, due to their small particle size, are very difficult objects for microscopic study and diagnostics of minerals. Using the method of scanning electron microscopy made it possible to obtain a visual idea of the forms of gold manifestation and its connection with sulfide minerals. Gold is found in concentrates in the form of: free grains; intergrowths with chalcopyrite (7-12 microns); inclusions in chalcopyrite (mainly) and pyrite. Free gold sizes vary from 5 to 20 microns; the size of gold inclusions in chalcopyrite and pyrite is 1-18 $\mu \mathrm{m}$ [7]. In some grains, intergrowths of rhombohedral or rhombohedral and cubic gold crystals with an uneven surface are observed, some areas of which are covered with a carbonaceous coating. Accumulations of "carbon", inclusions, coatings are observed both on flat areas of the surface, and in pits, in dents, at the intergrowth boundaries of crystals (Fig. 2).

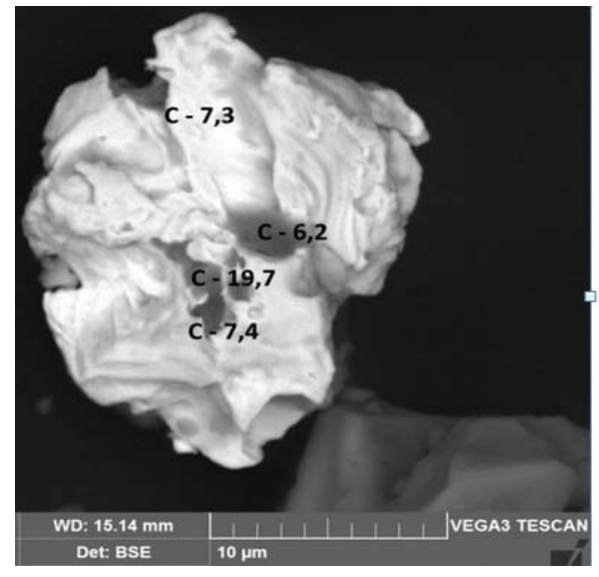

a

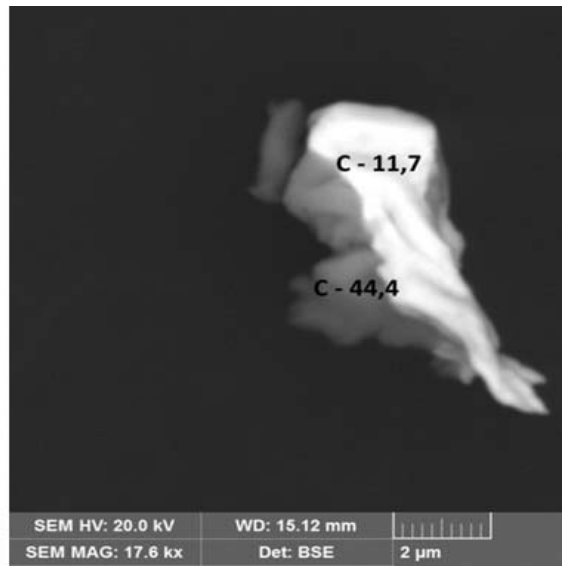

b

Fig. 2. SEM images of free gold (from flotation gold-copper concentrate) with carbon coatings: a - on an uneven surface; $b$ - on an uneven surface and the boundary of gold and chalcopyrite intergrowth

In the composition of gold, the following are permanently present: an admixture of silver $12-29 \%$; impurities of copper (1-5\%) and iron (1-3\%) from the host minerals; carbon $(6.6-19 \%)$, and in some cases up to $40 \%$ (Table 1, Fig. 2). 
Table 1. Gold composition in flotation gold-copper concentrates (SEM data)

\begin{tabular}{|l|c|c|c|c|c|c|c|c|}
\hline \multicolumn{1}{c}{$\begin{array}{c}\text { Gold (loose grains, } \\
\text { inclusions) }\end{array}$} & \multirow{2}{*}{$\begin{array}{c}\text { Size, } \\
\mu \mathrm{m}\end{array}$} & \multicolumn{7}{|c|}{ Element, \% } \\
\cline { 3 - 9 } & & $\mathrm{Au}$ & $\mathrm{Ag}$ & $\mathrm{Cu}$ & $\mathrm{Fe}$ & $\mathrm{Al}$ & $\mathrm{O}$ & $\mathrm{C}$ \\
\hline $\mathrm{Au}$ free & $15 \times 18$ & 74.5 & 12.4 & 1.4 & 0.9 & - & 3.2 & 7.3 \\
\hline $\mathrm{Au}$ free & $15 \times 17$ & 56.7 & 20.6 & 5.5 & 2.8 & - & 4.2 & 10.1 \\
\hline $\mathrm{Au}$ free & $8 \times 12$ & 62.2 & 22.2 & 1.8 & 1.2 & - & 2 & 10.6 \\
\hline $\mathrm{Au}$ free & $2,5 \times 8$ & 58.2 & 23.5 & 2.7 & 1 & - & 2.9 & 11.7 \\
\hline Inclusion of $\mathrm{Au}$ in $\mathrm{Cpy}$ & $15 \times 17$ & 60.9 & 21.5 & 1.3 & 1.1 & 0.6 & 7.3 & 7.3 \\
\hline Inclusion of $\mathrm{Au}$ in Py & $3,7 \times 4,7$ & 59.6 & 29 & 1.3 & 2.3 & - & 1.2 & 6.6 \\
\hline
\end{tabular}
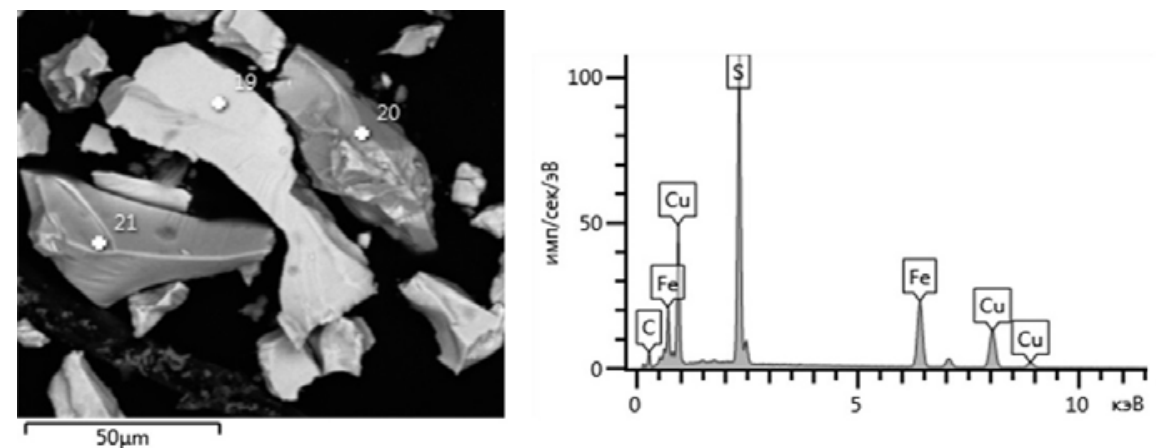

Fig. 3. SEM images of chalcopyrite crystals having on flat areas of their surface, edges, chips and microcracks thin carbonaceous deposits, coatings and accumulations.

Table 2. Composition of chalcopyrite and pyrite in flotation gold-copper concentrates (SEM data)

\begin{tabular}{|c|c|c|c|c|c|c|}
\hline \multirow{2}{*}{$\begin{array}{l}\text { Sulfide } \\
\text { minerals }\end{array}$} & \multirow{2}{*}{$\begin{array}{l}\text { Size, } \\
\mu \mathrm{m}\end{array}$} & \multicolumn{4}{|c|}{ Element, \% } & \multirow[t]{2}{*}{ Admixtures, intergrowths, inclusions } \\
\hline & & $\mathrm{Cu}$ & $\mathrm{Fe}$ & $\mathrm{S}$ & $\mathrm{C}$ & \\
\hline Chalcopyrite & $60 \times 80$ & 22 & 23.8 & 29.1 & 16.6 & $\mathrm{Si}-0.9 \% ; \mathrm{Al}-0.7 \% ; \mathrm{O}-6.9 \%$ \\
\hline Chalcopyrite & $5 \times 100$ & 32.2 & 28.8 & 31.8 & 6.90 & $\mathrm{Al}-0.3 \%$ \\
\hline $\begin{array}{l}\text { Chalcopyrite } \\
\text { in intergrowth }\end{array}$ & $55 \times 80$ & 30 & 27.1 & 32.4 & 10.5 & with host minerals \\
\hline Chalcopyrite & $40 \times 25$ & 35.7 & 31.5 & 16.6 & 14.3 & with galena inclusions \\
\hline Chalcopyrite & $40 \times 20$ & 31 & 25.2 & 32.2 & 11.6 & with galena and magnetite inclusions \\
\hline Chalcopyrite & $35 \times 30$ & 26.9 & 23.9 & 31.8 & 14.4 & with galena inclusions \\
\hline $\begin{array}{l}\text { Chalcopyrite } \\
\text { in intergrowth }\end{array}$ & $30 \times 15$ & 32.2 & 27.2 & 31.6 & 9.0 & with host minerals \\
\hline Chalcopyrite & $30 \times 12$ & 28.3 & 24 & 21.4 & 15.5 & $\mathrm{Si}$ - 1.3\%; Al - 1.1\%; O - 8.1\%; Ti - 0.3\% \\
\hline Chalcopyrite & $25 \times 17$ & 33.3 & 30.9 & 29.1 & 6.70 & - \\
\hline Chalcopyrite & $25 \times 10$ & 32.9 & 28.4 & 26.3 & 11.1 & $\mathrm{Al}-0.2 \% ; \mathrm{O}-1 \%$ \\
\hline Chalcopyrite & $20 \times 10$ & 29.5 & 25.3 & 29.4 & 12.7 & $\mathrm{O}-3.1 \%$ \\
\hline Chalcopyrite & $20 \times 10$ & 27.6 & 23.9 & 31.6 & 16.9 & with galena inclusions \\
\hline Pyrite & $75 \times 50$ & 1.6 & 38.3 & 39.9 & 17.2 & $\begin{array}{l}\text { with an admixture of copper and } \\
\text { galena inclusions }\end{array}$ \\
\hline 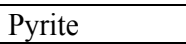 & $60 \times 70$ & - & 38.8 & 47.6 & 13.7 & with an admixture of copper, silver \\
\hline Pyrite & $50 \times 50$ & - & 44.8 & 47.8 & 7.36 & with an admixture of copper \\
\hline $\begin{array}{l}\text { Pyrite in } \\
\text { intergrowth }\end{array}$ & $50 \times 25$ & & 37.9 & 47.6 & 14.5 & with chalcopyrite \\
\hline $\begin{array}{l}\text { Pyrite in } \\
\text { intergrowth }\end{array}$ & $40 \times 25$ & - & 41.1 & 47.3 & 11.6 & with chalcopyrite \\
\hline $\begin{array}{l}\text { Pyrite in } \\
\text { intergrowth }\end{array}$ & $35 \times 35$ & - & 41.9 & 49.1 & 9.0 & with chalcopyrite \\
\hline $\begin{array}{l}\text { Pyrite in } \\
\text { intergrowth }\end{array}$ & $25 \times 30$ & & 39 & 48.1 & 12.9 & with chalcopyrite and galena \\
\hline
\end{tabular}


On flat areas of the surface of chalcopyrite crystals (in the composition of flotation concentrates), thin carbon deposits, coatings and accumulations are observed on edges, chips and microcracks. Probably, hydrophobic and hydrophobized coal microparticles attach and adhere to the hydrophobized areas of the surface of sulfide minerals. Chalcopyrite and pyrite contain 6-21\% carbon (Fig. 3, Table 2).

"Carbon" coatings can be selective for the surface of different minerals. This selectivity is determined by the fact that sulfide minerals (like carbon) are hydrophobic, while silicate and aluminosilicate minerals are hydrophilic [8]. In the tailings of copper selection, according to SEM data, on the surface of grains and crystals of quartz, the presence of coal suspensions was not detected; carbon was absent in the composition of quartz (Table 3).

Table 3. Composition of some quartz grains in copper tailings (SEM data)

\begin{tabular}{|l|c|c|c|c|}
\hline \multirow{2}{*}{ Barren minerals } & \multirow{2}{*}{$\begin{array}{c}\text { Size, } \\
\end{array}$} & \multicolumn{2}{|c|}{ Element, \% } & \multirow{2}{*}{$\begin{array}{c}\text { Admixtures, intergrowths, } \\
\text { inclusions }\end{array}$} \\
\cline { 3 - 4 } & $90 \times 100$ & 45.5 & 54.5 & \\
\hline Quartz & $15 \times 20$ & 45.2 & 54.2 & $\mathrm{Cu}-0.4 \% ; \mathrm{Fe}-0.2 \%$ \\
\hline Quartz & $20 \times 30$ & 45.2 & 52.9 & $\mathrm{Cu}-0.5 \% ; \mathrm{Fe}-0.7 \% ; \mathrm{S}-8.1 \%$ \\
\hline $\begin{array}{l}\text { Quartz intergrowth } \\
\text { with chalcopyrite }\end{array}$ & &
\end{tabular}

In the tailings of copper selection, sludge aggregates with an increased carbon content (up to $32 \%$ ) were also observed. Fine slurry particles have a large specific surface area and absorb much more reagent from the pulp than large particles. The reduced flotation rate of sludge particles is associated with their specific surface area. To extract even small weight amounts of sludge, a huge amount of highly dispersed bubbles is required [2]. These provisions of Glembotskiy, in the authors' opinion, are also valid for fine coal particles. Fig. 4 displays an aggregate $\sim 30 \mu \mathrm{m}$ in size, in the center of which crystals of magnetite are observed (with the inclusion of chalcopyrite, admixtures of $\mathrm{Ti}$ and $\mathrm{Cr}$ ); on the surface of the aggregate there are carbonaceous and aluminosilicate sludge coatings.
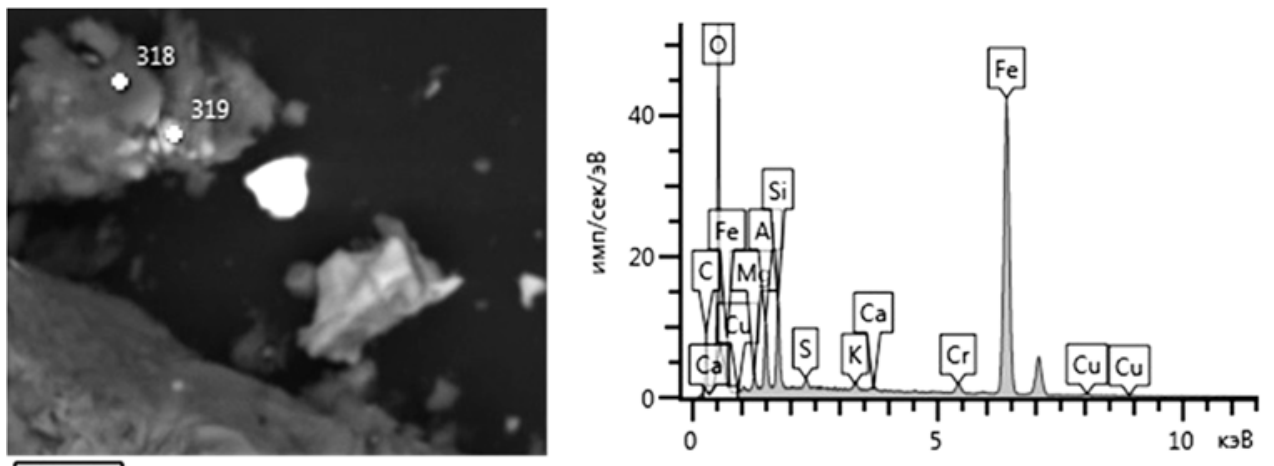

$10 \mu \mathrm{m}$

Fig. 4. SEM image of an aggregate (from copper selection tailings) containing magnetite crystals (with inclusions of chalcopyrite, admixtures of $\mathrm{Ti}$ and $\mathrm{Cr}$ ), carbonaceous and aluminosilicate sludge coatings on the aggregate surface

\section{Conclusions}

The quality of the obtained gold-copper concentrates is confirmed by the efficiency of using activated carbon to reduce the excess of reagents accumulating in the collective concentrates. Detailed studies of concentrates of copper selection using scanning electron microscopy revealed the presence of carbon in their composition. On the surface of gold and chalcopyrite particles, thin coal deposits and coatings were observed. Flotation of 
particles of gold and sulfide minerals can probably be improved by naturally hydrophobic or hydrophobized coal particles. "Carbon" coatings are selective with respect to the surface of sulfide minerals. No carbon coatings were found on the surface of quartz grains and crystals.

Technological studies were carried out on the basis of the TsIMS Center for Collective Use of the Institute of Mining of the FEB RAS.

\section{References}

1. A.A. Abramov, Technology of processing and concentration of non-ferrous metal ores, 1 (2005)

2. V.A. Glembotskiy, V.I. Klassen, Flotation enrichment methods (1981)

3. O.S. Bogdanov, Yu.I. Eropkin, A.K. Podnek, Study of the action of flotation reagents (1965)

4. D. Salatic, V. Salatic, Development in mineral processing. Proceeding of the XXI IMPC, C, xxii (2000)

5. S.M. Bulatovic, Handbook of Flotation Reagents: Chemistry, Theory and Practice Flotation of Industrial Minerals, 3 (2015)

6. M.A. Gurman, E. D. Shepeta, A.E. Poltaretskaya, Yu.A. Vasyanovich, Problems of geo-resource development in the Far East, 42 (2019)

7. M.A. Gurman, L.I. Shcherbak, Scientific Foundations and Practice of Processing Ores and Technogenic Raw Materials, 49 (2020)

8. B.A. Zakharov, M.A. Meretukov, Gold: refractory ores (2013) 